\title{
The Association between Depression and Suicidal Ideation A Systematic Review and Meta-Analysis
}

\author{
Kaleab Tesfaye Tegegne ${ }^{1}$, Eleni Tesfaye Tegegne ${ }^{2}$, Mekibib Kassa Tessema ${ }^{3}$, Wosenyeleh Semeon Bagajjo ${ }^{4}$, Muse Rike ${ }^{5}$ Alelign Tadele \\ Abebe $^{6}$, Berhanu Bifato ${ }^{1}$ \\ ${ }^{1}$ Department of public health, Hawassa College of health science, hawassa, Ethiopia. \\ ${ }^{2}$ College of medicine and health science, school of nursing, university of gondar, gondar, Ethiopia. \\ ${ }^{3}$ Leishmania research and treatment center, university of gondar, gondar, Ethiopia. \\ ${ }^{4}$ Dean of Hawassa College of health science, hawassa, Ethiopia. \\ ${ }^{5}$ Research and publication directorate, Hawassa College of health science, hawassa, Ethiopia. \\ ${ }^{6}$ Department of medical laboratory technology, Hawassa College of health science, hawassa, Ethiopia.
}

Corresponding Author: Kaleab Tesfaye Tegegne, Department of public health, Hawassa College of health science, hawassa, Ethiopia.

Received date: September 23, 2021; Accepted date: November 12, 2021; Published date: January 03, 2022

Citation: Kaleab Tesfaye Tegegne, Eleni Tesfaye Tegegne, Mekibib Kassa Tessema, Wosenyeleh Semeon Bagajjo, Muse Rike and Alelign Tadele Abebe, Berhanu Bifato (2022) The Association between Depression and Suicidal Ideation A Systematic Review and Meta-Analysis. J. Psychology and Mental Health Care, 6(1): DOI: 10.31579/2637-8892/145

Copyright: (c) 2022, Kaleab Tesfaye Tegegne, This is an open access article distributed under the Creative Commons Attribution License, which permits unrestricted use, distribution, and reproduction in any medium, provided the original work is properly cited.

\begin{abstract}
The purpose of this meta-analysis was to assess the association between Depression and suicidal ideation. We use data from six studies to do a meta-analysis. We applied the random-effects analytic model and calculated a pooled odds ratio.

The combined effect size showed that odds of suicidal ideation among people with Depression is 4.88 times higher than those peoples without Depression (ORMH $4.8895 \%$ CI 2.04, 11.72) Test for overall effect: $\mathrm{Z}=3.55$ ( $\mathrm{P}=$ 0.0004) Heterogeneity: $\mathrm{Tau}^{2}=1.11 ; \mathrm{Chi}^{2}=100.97$, df $=5(\mathrm{P}<0.00001) ; \mathrm{I}^{2}=95 \%$. The magnitude of suicidal ideation among people with Depression is $46.39 \%$ (528) and peoples without Depression is $17.79 \%$ (315) from the total, $39.13 \%$ (1138) is depressed and $60.86 \%$ (1779) not depressed. The overall proportion of Suicidal Ideation among the included studies is $28.98 \%$ (843). The total number of study subjects included in our systematic review and meta-analysis is 2908 .
\end{abstract}

Key word: depression, suicidal ideation, ethiopia

\section{Introduction}

The Diagnostic and Statistical Manual of Mental Disorders defines suicidal ideation as a thinking about, making plans for suicide and selfdestructive act with a clear expectation of death that is non-fatal [1]. The magnitude of suicide indicates as it is a serious public health problem in the world [2]. It affects more than 50 million people in the world [3]. The worldwide prevalence of suicide is estimated to raise to $2.4 \%$ by 2020 year, and the rate of death due to suicide will be one person every $20 \mathrm{~s}$ [4]. It is the second leading cause of death among adolescents and young adults [5-6]. Suicidal acts result from a combination of biological, psychological, sociological, cultural and environmental factors [7].

Depression is the top risk factor and risk factors for suicidal ideation can be divided into 3 categories: psychiatric disorders, life events, and family history [8]. The most frequently reported factors correlated with suicidal behavior are being male, psychological distress [9], depression [10], dissatisfaction with academic performance, feeling neglected by parents [11-12], substance abuse, psychiatric disorders [13], drug use [14], depressive symptoms [15], first year and pre-clinical phase, homesick [16], alteration in thyroid, and prolactin hormone [17].

The loss of loved one by suicide and emotional turmoil related to bereavement also linked with increase in suicidal behavior [18]. There is also a strong positive correlation of suicide in those who are young age, male and a higher level of education [19]. However, there are limited data specifically on the association between Depression and suicide ideation.

Therefore, this study aimed to assess the association between Depression and suicidal ideation. This study would help as an input of information 
for health providers /psychiatrists on the relationship between depression and suicidal ideation and leads to plan suicide prevention strategies

\section{Materials and methods}

\section{Data}

Electronic databases were searched .on reference manager software and quality assessments of the included studies were performed by assessing the risk of bias. A meta-analysis was applied to test the association between Depression and suicidal ideation. Words used to search literatures are, 'factors associated with suicidal ideation and suicidal ideation.

\section{Study selection}

Figure 1 shows the selection process of the articles searched. The initial search on reference manager software results in 89 and after duplicates removed 47 records remain and 14 studies assess for eligibility and finally 6 studies included in our systematic review and meta-analysis

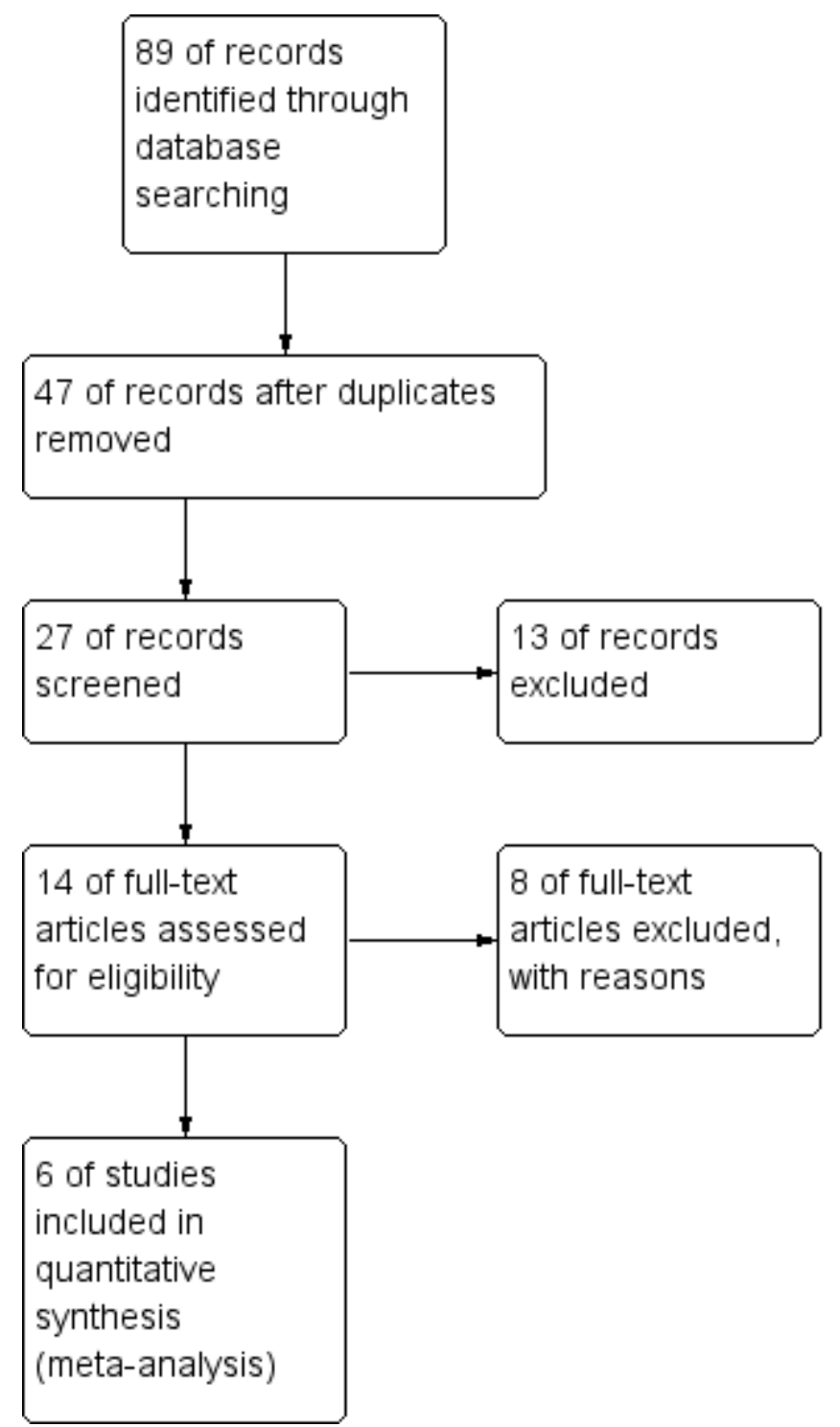

\section{Figure 1. Study flow diagram}

\section{Measures}

Suicidal ideation was the outcome variable depression was the exposure. The two variables measured in deferent way in different studies included in our systematic review and met analysis

\section{Analysis}

By design, this study is secondary data analysis. Using Review Manager Version 5.3 software and Meta Essential software. We determined combined effect size and associated $95 \%$ confidence intervals to describe the relationship between Depression and Suicidal ideation. We calculated combined effect size across the studies using the Mantel-Haenszel (MH) statistic (the DerSimonian-Laird method or random effect model).

We applied the random effects analytic model to account for inter survey variation and to provide a more conservative effect than a fixed model would have provided. The I ${ }^{2}$ statistics were used to assess the variability among the included studies and above $50 \%$ was considered as significant.

\section{Result}

The characteristics of included studies according to sample size. Depression and Suicidal Ideation. 


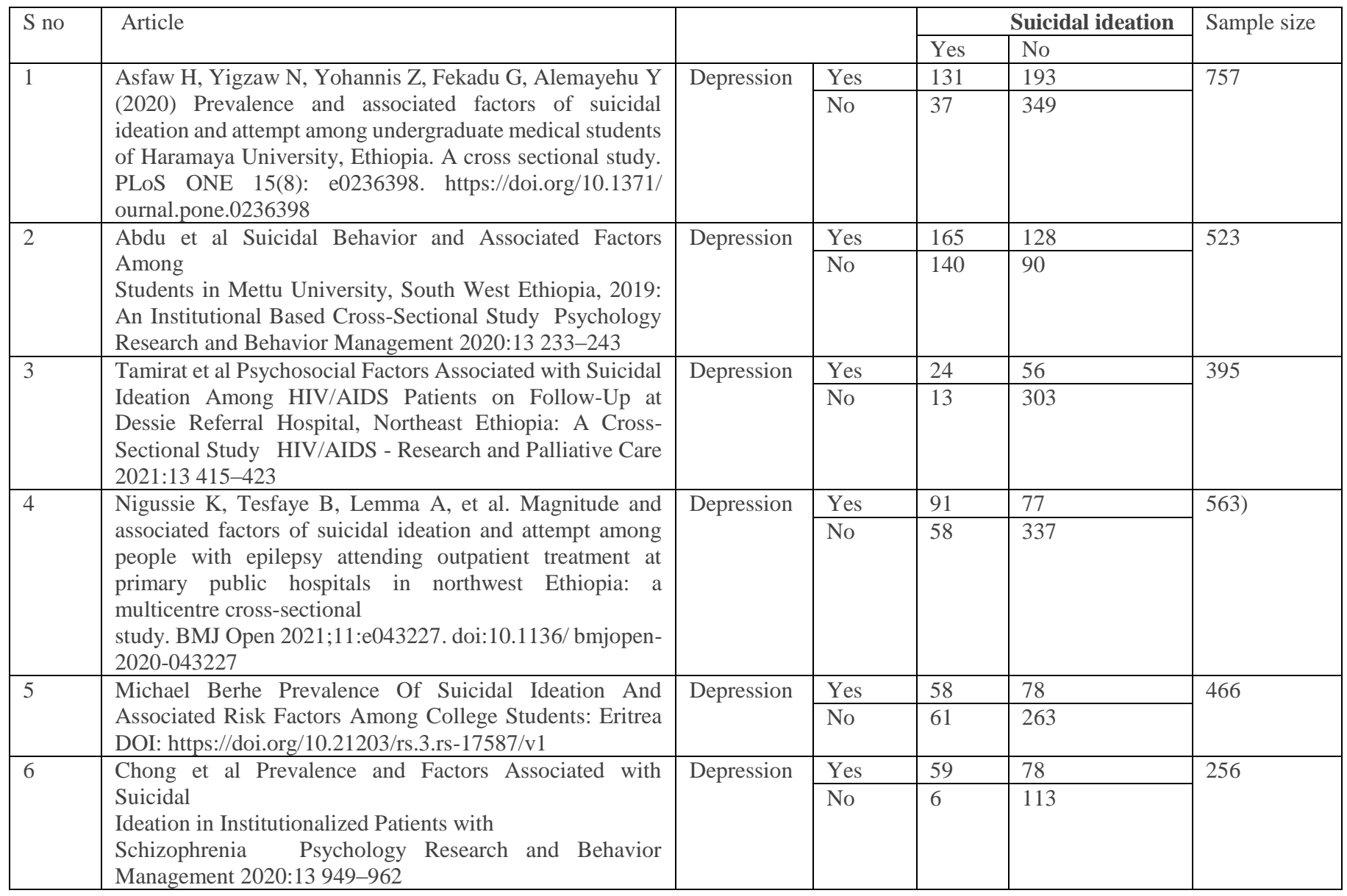

Table 1. Characteristics of the included studies

The magnitude of suicidal ideation among people with Depression is $46.39 \%$ (528) and peoples without Depression is $17.79 \%$ ( 315 ) from the total, $39.13 \%$ ( 1138) is depressed and 60.86\% (1779) not depressed. The overall proportion of Suicidal Ideation among the included studies is

\section{Depression No Depression}

Study or Subgroup

Events Total Events

$165-203-140$

140

Total

$230 \quad 17.4$

Asfaw $\mathrm{H}_{\text {, et al }}$

Berhe.M et al

Chong et al

Nigussie Ket al

Tamirat et al

$131 \quad 324$

$58 \quad 136$

$59 \quad 137$

$91 \quad 168$

$24 \quad 80$

37

$386 \quad 17.2 \%$

$61 \quad 324 \quad 17.1 \%$

$6 \quad 119 \quad 15.1 \%$

$\begin{array}{lll}58 & 395 & 17.2 \%\end{array}$

13

316

$1770 \quad 100.0 \%$

Total (95\% Cl)

Total events

1138

528

Heterogeneity. Tau $^{2}=1.11 ; \mathrm{Chi}^{2}=100.97, \mathrm{df}=5(\mathrm{P}<0.00001) ;\left.\right|^{2}=95 \%$

Test for overall effect: $Z=3.55(P=0.0004)$ 315

$28.98 \%$ ( 843). The total number of study subjects included in our systematic review and meta-analysis is 2908 .

\section{Meta-analysis}

Odds Ratio

Odds Ratio

M-H, Random, $95 \% \mathrm{Cl}$

$0.83[0.58,1.18]$
$6.40[4.27,9.60]$
$3.21[2.07,4.97]$
$14.25[5.86,34.62]$
$6.87[4.55,10.37]$
$9.99[4.80,20.78]$

$4.88[2.04,11.72]$

Figure 2, Forest plot for the association between Depression and suicidal ideation

The combined effect size showed that odds of suicidal ideation among people with Depression is 4.88 times higher than those peoples without Depression (ORMH 4.88 95\%CI 2.04, 11.72) Test for overall effect: $Z=$
$3.55(\mathrm{P}=0.0004)$ Heterogeneity: $\mathrm{Tau}^{2}=1.11 ; \mathrm{Chi}^{2}=100.97, \mathrm{df}=5(\mathrm{P}<$ $0.00001) ; \mathrm{I}^{2}=95 \%$.

\section{Assessment of publication bias}




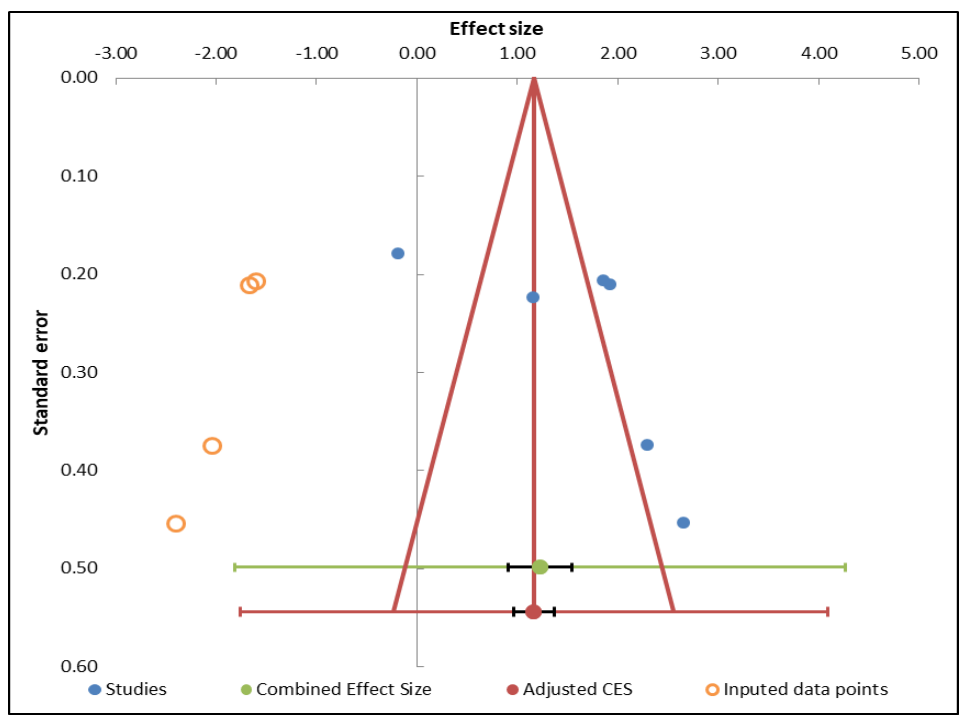

Figure 3. Funnel plot for the association between Depression and suicidal ideation

\begin{tabular}{|c|c|c|c|c|}
\hline \multicolumn{4}{|c|}{ Egger Regression } & \multirow[b]{2}{*}{ CI UL } \\
\hline & Estimate & SE & CI LL & \\
\hline Intercept & 8.66 & 5.72 & -6.05 & 23.38 \\
\hline Slope & -0.72 & 1.34 & -4.17 & 2.73 \\
\hline $\mathrm{t}$ test & 1.51 & & & \\
\hline$p$-value & 0.205 & & & \\
\hline \multicolumn{2}{|c|}{ Begg \& Mazumdar } & & & \\
\hline$\Delta_{x-y}$ & 1.00 & & & \\
\hline Kendall's Tau a & 0.07 & & & \\
\hline $\mathrm{Z}$ & 0.19 & & & \\
\hline $\mathrm{P}$ & 0.851 & & & \\
\hline & & & & \\
\hline
\end{tabular}

As funnel plot showed there is no publication bias Egger Regression $\mathrm{p}$ value $=-0.205$ Begg \& Mazumdar $\mathrm{p}$ value $=0.851$.

\section{Source of heterogeneity}

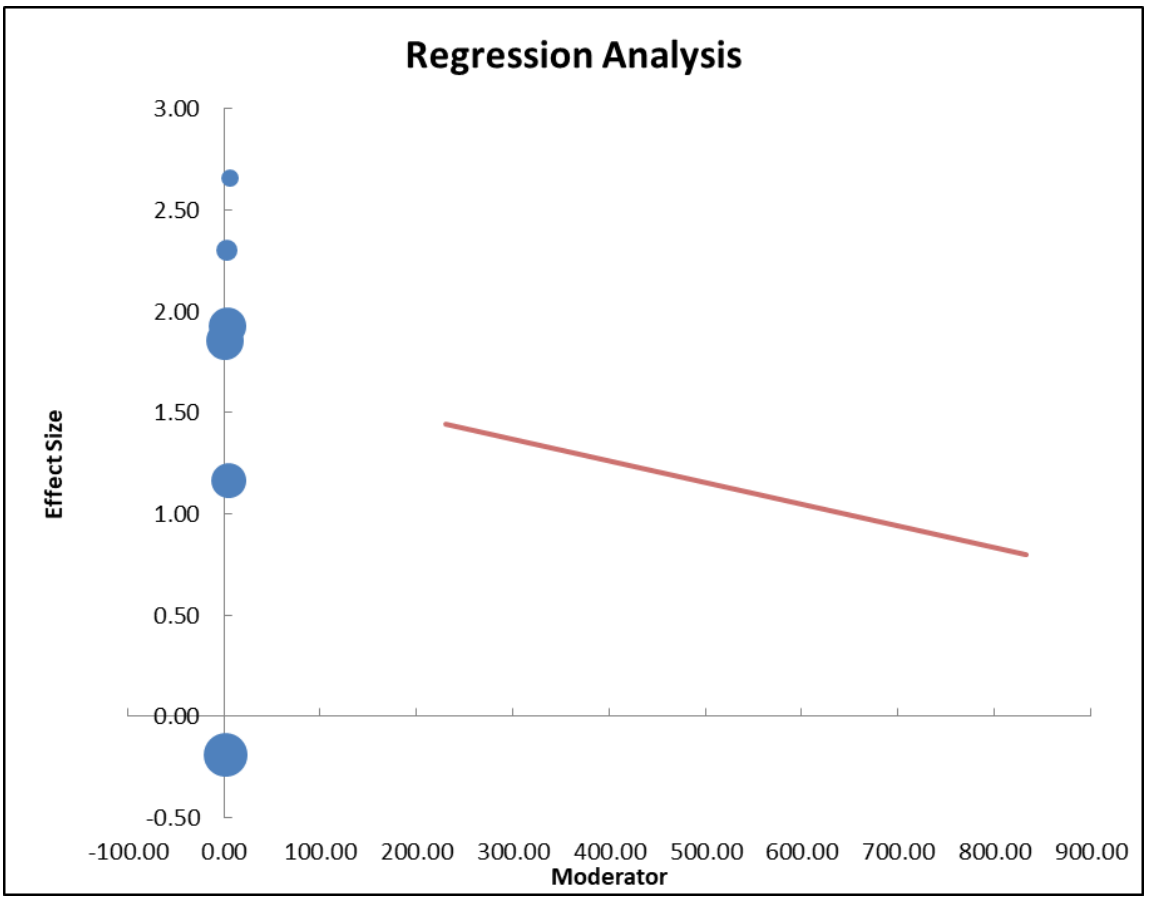




\begin{tabular}{|l|l|l|l|l|l|l|l|}
\hline & B & SE & CI LL & $\begin{array}{l}\text { CI } \\
\text { UL }\end{array}$ & $\boldsymbol{\beta}$ & $\begin{array}{l}\text { Z- } \\
\text { value }\end{array}$ & $\begin{array}{l}\text { p- } \\
\text { value }\end{array}$ \\
\hline Intercept & 1.69 & 0.19 & 1.20 & 2.17 & & 8.96 & 0.000 \\
\hline Moderator & 0.00 & 0.00 & 0.00 & 0.00 & \#VALUE! & -2.85 & 0.004 \\
\hline \hline
\end{tabular}

Figure 4. Moderator analysis for the association between Depression and suicidal ideation

As sample size increase the effect size decrease $(B=0.00 \mathrm{p}$ Value $=0.004)$, so the source of heterogeneity is sample size difference of the included studies

\section{Discussion}

This study is similar with previous studies in USA (20), Colombia, (21), Brazil (22), China (10) Nepal (11), Washington (23), Canada,(24), Bosnia and Herzegovina (25), Poland (26), Brazil (27), Malaysia (28), South Africa (29), Nigeria(30), Eriteria [8], in India (31), Ethiopia (3235), Addis Ababa Ethiopia [36]. This may be due to high depressive symptoms that are related to suicidal risk and thoughts. A Depression that affects everyday activities, social interactions, and low self-esteem can cause increased suicidal thoughts. Many of this previous studies explained that the presence of depression is highly associated with suicidal ideation. It also indicated that the decreased level of serotonin neurotransmitter in the brain of a depressed individual was found to be associated with increased suicidal behavior [37].

The possible explanation may also be due to a direct effect of depression which makes individuals to feel hopeless, isolated and worthless [17]. The other possible explanation might be due to high levels of stress associated with adjusting to a new social environment and could be due to the effect of high dose of alcohol consumption [8]. This systematic review and meta-analysis is inconsistence with previous study [38]. The reason for the difference between our findings and this study may be the difference in sample size, study population and study participants characteristic. This study indicated that depressed persons have higher risk of suicidal ideation than no depressed persons and health provider should give focus or priority to identify depressed people as well as to assess risk of suicide in depressed people.

\section{Conclusion}

This study showed that peoples with Depression are more likely to have suicidal ideation than people without Depression

\section{Data Availability:}

All data are included in the paper.

\section{Conflicts of Interest:}

The authors declare that they have no conflicts of interest.

\section{Authors' Contributions:}

- Kaleab Tesfaye Tegegne, Eleni Tesfaye Tegegne and Mekibib Kassa Tessema were responsible for conceptualization, project administration, software, supervision, and development of the original drafting of the manuscript.

- Kaleab Tesfaye Tegegne, Eleni Tesfaye Tegegne , Wosenyeleh Semeon Bagajjo, and Mekibib Kassa Tessema, Muse Rike , Alelign Tadele Abebe, Berhanu Bifato 1were participated in quality assessment of articles, methodology, validation, and screening of research papers

- All authors contributed with data analysis, critically revised the paper, and agreed to be accountable for their contribution.

\section{Acknowledgments}

We would like to thank all the primary authors of the included articles.

\section{Declaration}

\section{Ethics approval and consent to participate}

Not applicable

\section{Competing of interest}

The authors have declared that there is no competing interest

\section{Consent for publication}

Not applicable

\section{Funding}

Not any funding received for this work

\section{Reference}

1. Association AP. Diagnostic and statistical manual of mental disorders (DSM-5®). American Psychiatric Pub, 2013.

2. Rudd MD. (2008) Suicide warning signs in clinical practice. Curr Psychiatry Rep, 10:87-90.

3. Organization WH. WHO-AIMS: mental health systems in selected low-and middle-income countries: a WHO-AIMS cross-national analysis. World Health Organization, 2010.

4. Organization WH. Preventing suicide: a global imperative. World Health Organization, 2014

5. Bertolote J.M. and Fleischmann A., (2002) A global perspective in the epidemiology of suicide. Suicidologi, 7(2): p. $6-8$.

6. Chikwande M.J., (2017) Experiences of bereavement and coping strategies among people who have lost their significant others to suicide.

7. Czerwik-Kulpa M, Chylińska J. (2010) Quality of life in palliative care. Acta Neuropsychologica, 8:244-62

8. Prevalence Of Suicidal Ideation And Associated Risk Factors Among College Students: Eritrea Michael Berhe (mikidadimakaku@gmail.com) Elabered entomology lab yonas Tewelde ACHS Filimon yohanes ACHS Haben Berhane ACHS

9. Sun L., et al., (2017) Suicidal ideation, plans and attempts among medical college students in china: the effect of their parental characteristics. Psychiatry research, 247: p. 139-143.

10. Sobowale K., et al. (2014) Depression and suicidal ideation in medical students in China: a call for wellness curricula. International journal of medical education, 5: p. 31.

11. Adhikari A., et al. (2017) Prevalence of poor mental health among medical students in Nepal: a cross-sectional study. $B M C$ medical education, 17(1): p. 232.

12. Menezes R.G., et al. (2012) Suicidal ideation among students of a medical college in Western Nepal: a crosssectional study. Legal Medicine, 14(4): p. 183-187.

13. Osama M., et al. (2014) Suicidal ideation among medical students of Pakistan: a cross-sectional study. Journal of forensic and legal medicine, 27: p. 65-68.

14. McClelland K.I. and Davies T.H. (2019) Understanding Links among Opioid Use, Overdose, and Suicide. The New England journal of medicine, 380(14): p. 1379-1380,

15. Van Niekerk L., Scribante L., and Raubenheimer P. (2012) Suicidal ideation and attempt among South African medical 
students. SAMJ: South African Medical Journal, 102(6): p. 372-373.

16. Ahmed S., Omar Q.H., and Elamaim A.A.A. (2016) Forensic analysis of suicidal ideation among medical students of Egypt: a crosssectional study. Journal of forensic and legal medicine, 44: p. 1-4.

17. Pompili M., et al. (2012) Prolactin and thyroid hormone levels are associated with suicide attempts in psychiatric patients. Psychiatry Res, 200(2-3): p. 389-94.

18. Pompili M., et al. (2013) Bereavement after the suicide of a significant other. Indian Journal of Psychiatry, 55(3): p. 256.

19. Cassidy RM, Yang F, Kapczinski F, Passos IC. (2018) Risk factors for suicidality in patients with schizophrenia: a systematic review, meta-analysis, and meta-regression of 96 studies. Schizophr Bull. 44(4):787-797.

20. Schwenk T.L., Davis L., and Wimsatt L.A., (2010) Depression, stigma, and suicidal ideation in medical students. Jama, 304(11): p. 1181-1190.

21. Pinzo'n-Amado A., et al. (2013) Suicide ideation among medical students: prevalence and associated factors. Revista colombiana de psiquiatria, 42: p. 47-55.

22. Coentre R., Faravelli C., and Figueira M.L. (2016) Assessment of depression and suicidal behaviour among medical students in Portugal. International journal of medical education, 7: p. 354.

23. Hecimovic H, Santos JM, Carter J, et al. (2012) Depression but not seizure factors or quality of life predicts suicidality in epilepsy. Epilepsy \& Behavior, 24:426-9.

24. Altura KC, Patten SB, Fiest KM, et al. (2016) Suicidal ideation in persons with neurological conditions: prevalence, associations and validation of the PHQ-9 for suicidal ideation. Gen Hosp Psychiatry, 42:22-6.

25. Loga Andrijić N, Alajbegović A, Loga Zec S. (2014) Suicidal ideation and thoughts of death in epilepsy patients. Psychiatria Danubina, 26:0-55

26. Bosak M, Turaj W, Dudek D, et al. (2016) Suicidality and its determinants among Polish patients with epilepsy. Neurol Neurochir Pol, 50:432-8.

27. de Oliveira GNM, Kummer A, Salgado JV, et al. (2011) Suicidality in temporal lobe epilepsy: measuring the weight of impulsivity and depression. Epilepsy Behav, 22:745-9.

28. Rani RA, Razali R, Hod R. (2014) Suicidal ideation amongst epilepsy patients in a tertiary centre. Neurology Asia;19.
29. Lim H-W, Song H-S, Hwang Y-H, et al. (2010) Predictors of suicidal ideation in people with epilepsy living in Korea. J Clin Neurol, 6:81-8.

30. Van Niekerk L., Scribante L., and Raubenheimer P. (2012) Suicidal ideation and attempt among South African medical students. SAMJ: South African Medical Journal, 102(6): p. 372-373

31. Nuhu FT, Lasisi MD, Yusuf AJ, et al. (2013) Suicide risk among adults with epilepsy in Kaduna, Nigeria. Gen Hosp Psychiatry, 35:517-20

32. K Nagendra ,D Sanjay el at., (2010) Prevalence And Association Of Depression And Suicidal Tendency Among Adolescent Students: International Journal Of Biomedical And Advance Research Vinodmicro@ Yahoo.ComIn

33. Tamirat et al. (2021) Psychosocial Factors Associated with Suicidal Ideation Among HIV/AIDS Patients on Follow-Up at Dessie Referral Hospital, Northeast Ethiopia: A CrossSectional Study HIV/AIDS - Research and Palliative Care, 13 415-423

34. Gebremariam EH, Reta MM, Nasir Z, Amdie FZ. (2017) Prevalence and associated factors of suicidal ideation and attempt among people living with HIV/AIDS at Zewditu Memorial Hospital, Addis Ababa, Ethiopia: a cross-sectional study. Psychiatry j. 2017:1-8.

35. Nigussie K, Tesfaye B, Lemma A, et al. (2021) Magnitude and associated factors of suicidal ideation and attempt among people with epilepsy attending outpatient treatment at primary public hospitals in northwest Ethiopia: a multicentre crosssectional study. BMJ Open 11:e043227.

36. Asfaw H, Yigzaw N, Yohannis Z, Fekadu G, Alemayehu Y (2020) Prevalence and associated factors of suicidal ideation and attempt among undergraduate medical students of Haramaya University, Ethiopia. A cross sectional study. PLoS ONE 15(8): e0236398.

37. Haile K, Awoke T, Ayano G, et al. (2018) Suicide ideation and attempts among people with epilepsy in Addis Ababa, Ethiopia. Ann Gen Psychiatry, 17:4

38. Courtet P, Baud P, Abbar M, et al. (2001) Association between violent suicidal behavior and the low activity allele of the serotonin transporter gene. Mol Psychiatry, 6:338-41

39. Abdu et al. (2020) suicidal Behavior and Associated Factors Among Students in Mettu University, South West Ethiopia, 2019: An Institutional Based Cross-Sectional Study Psychology Research and Behavior Management, 13 233-243.

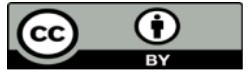

This work is licensed under Creative Commons Attribution 4.0 License

To Submit Your Article Click Here:

Submit Manuscript

DOI: $10.31579 / 2637-8892 / 145$

\author{
Ready to submit your research? Choose Auctores and benefit from: \\ $>$ fast, convenient online submission \\ $>$ rigorous peer review by experienced research in your field \\ $>$ rapid publication on acceptance \\ $>$ authors retain copyrights \\ $>$ unique DOI for all articles \\ $>$ immediate, unrestricted online access
}

At Auctores, research is always in progress.

Learn more https://auctoresonline.org/journals/psychology-and-mental-healthcare 